\title{
Eribulin, trastuzumab, and pertuzumab as first-line therapy for patients with HER2-positive metastatic breast cancer: a phase II, multicenter, collaborative, open-label, single-arm clinical trial
}

\author{
Kenichi Inoue ${ }^{1}$ (D) Jun Ninomiya ${ }^{2} \cdot$ Tsuyoshi Saito $^{3} \cdot$ Katsuhiko Okubo $^{4} \cdot$ Takashi Nakakuma $^{5} \cdot$ Hirofumi Yamada $^{6} \cdot$ \\ Kei Kimizuka ${ }^{7}$. Tohru Higuchi ${ }^{3}$. for the SBCCSG-36 investigators
}

Received: 29 January 2019 / Accepted: 1 March 2019 / Published online: 8 March 2019

(C) The Author(s) 2019, corrected publication 2019

\begin{abstract}
Summary
Purpose To examine the efficacy and safety of triple therapy with eribulin, trastuzumab, and pertuzumab in patients with HER2positive metastatic breast cancer (MBC) who never received any prior therapy in the first-line metastatic/advanced setting. Methods Eribulin $1.4 \mathrm{mg} / \mathrm{m}^{2}$ (days 1 and 8), trastuzumab $8 \mathrm{mg} / \mathrm{kg}$ over $90 \mathrm{~min}$ and $6 \mathrm{mg} / \mathrm{kg}$ over $30 \mathrm{~min}$, and pertuzumab $840 \mathrm{mg} /$ body over $60 \mathrm{~min}$ and $420 \mathrm{mg} /$ body over $30 \mathrm{~min}$ were administered intravenously in 21-day cycles. Results 25 women (median age, 57 years [range, 41-75 years]) received a median of 10 cycles (range, 0-34 cycles); 24 had performance status (PS) 0, 1 PS 1, 8 stage IV breast cancer, and 17 recurrence. Lung and liver metastases occurred in 9 and 9 patients, respectively. Median time to treatment failure with eribulin was 9.1 months (95\% confidence interval [CI], 4.3-13.9 months), and median progression-free survival was 23.1 months (95\% CI, 14.4-31.8 months). The overall response rate (complete response [CR] + partial response [PR]) was $80.0 \%$ (95\% CI, 59.3-93.2\%), and the clinical benefit rate (CR + PR + stable disease $\geq 24$ weeks) was $84.0 \%$ (95\% CI, 63.9-95.5\%). The most common treatment-emergent adverse events (TEAEs) were alopecia (92.0\%), fatigue $(68.0 \%)$, and sensory peripheral neuropathy $(60.0 \%)$. Grade $3 / 4$ TEAEs occurred in 11 patients $(44.0 \%)$. The only grade 4 TEAE was neutrophil count decreased $(16.0 \%)$. Neither grade 4 peripheral neuropathy nor febrile neutropenia occurred. Conclusions ETP therapy showed acceptable efficacy and safety and is a potential first-line therapy for patients with HER2-positive MBC.
\end{abstract}

Keywords Metastatic breast cancer $\cdot$ Eribulin $\cdot$ Trastuzumab $\cdot$ Pertuzumab $\cdot$ HER2-positive $\cdot$ First-line therapy

Some results of this study were presented as posters at the San Antonio Breast Cancer Symposium, San Antonio, TX, USA, December 4-8, 2018.

Kenichi Inoue

ino.bad.ken@gmail.com

1 Division of Breast Oncology, Saitama Cancer Center, 780 Komuro, Ina-machi, Kita-adachi-gun, Saitama 362-0806, Japan

2 Department of Breast Surgery, Ninomiya Hospital, Soka, Japan

3 Department of Breast Surgery, Saitama Red Cross Hospital, Saitama, Japan

4 Department of Breast Unit, Toda Central General Hospital, Saitama, Japan

5 Department of Breast Surgery, Ageo Central General Hospital, Ageo, Japan

6 Department of Surgery, Sekishindo Hospital, Saitama, Japan

7 Department of Breast Surgery, Kasukabe Medical Center, Kasukabe, Japan

\section{Introduction}

The amplification of the human epidermal growth factor receptor 2 (HER2)/neu oncogene occurs in 25 to $30 \%$ of breast cancers, which increases the aggressiveness of the malignancy $[1,2]$. Up to $5 \%$ of patients present with distal metastases at the time of diagnosis [3], and an additional 10 to $15 \%$ of patients will develop metastasis within 3 years after diagnosis [4]. Despite remarkable progress in the treatment of HER2positive breast cancer, metastatic breast cancer (MBC) is still incurable in the majority of patients [5].

Two randomized clinical studies of trastuzumab in combination with conventional chemotherapy (doxorubicin, epirubicin, cyclophosphamide, or paclitaxel) [6] and a taxane (docetaxel) [7] showed that the combined therapy arms increased the response rates and extended the median time to treatment failure (TTF) and the median overall survival (OS) as compared with the control treatment arms. Therefore, the therapeutic regimen combining trastuzumab and a taxane was 
recommended for patients with HER2-positive MBC. Results from a phase III, placebo-controlled clinical trial of docetaxeltrastuzumab-pertuzumab (DTP) for patients with HER2positive MBC (CLEOPATRA Study) [8] led to the approval of the triple regimen by the Food and Drug Administration (FDA) as the first "first-line" therapy. Additional confirmatory clinical data from the CLEOPATRA Study $[9,10]$ demonstrated the statistically significant and clinically meaningful survival benefit of DTP therapy; progression-free survival (PFS) assessed by the investigator and safety were consistent between the updated and primary analyses. Hence, DTP therapy is currently a well-established first-line therapy for this patient population. Nevertheless, docetaxel is often difficult to administer continuously due to its acute and/or cumulative toxicities (e.g., infusion reaction, febrile neutropenia, nail toxicities, fatigue, edema, rash, and peripheral neuropathy) [11].

Eribulin is a structurally simplified synthetic macrocyclic ketone analogue of halichondrin B [12] with a unique mechanism of action - binding to the high affinity sites on the growing plus $(+)$ ends of microtubules appearing different from the taxane- and vinca-binding sites [13] — and showed potent anticancer activity and an acceptable safety profile in 7 phase II clinical trials for patients with MBC [14-19]. Furthermore, a global, multicenter, randomized, open-label, phase III clinical trial of eribulin (Study 305/ EMBRACE) showed statistically significant and clinically meaningful improvements in OS compared to treatment of physician's choice (most often including vinorelbine, gemcitabine, and capecitabine) in women with heavily pretreated MBC [20]. The landmark study led to the approval of eribulin by the FDA for the treatment of MBC in patients who had received at least two prior chemotherapy regimens. Another phase III clinical study of eribulin and capecitabine (Study 301) indicated the ORRs, PFSs, OSs, and overall quality of life (QOL) scores, all of which were comparable but without statistically significant differences between the study groups [21]. Furthermore, the pooled analysis of these two phase III studies confirmed the significant survival benefit of eribulin compared to control after treatment with a taxane and an anthracycline in patients with MBC [22]. Thus, eribulin showed therapeutic benefits in phase II/III clinical trials [14-22]. Furthermore, a retrospective observational study of eribulin in Japanese women with MBC [23] - which explored the extrapolation of these findings to the real-world clinical settings-suggested that the safety profile of eribulin in real-world clinical practice may be considered more acceptable than that reported in some of these studies.

Based on a wealth of clinical evidence mentioned above, we made a hypothesis that eribulin is superior to docetaxel in safety and tolerability and allows longer-term triple therapy. The objective of the present study was to examine the efficacy and safety of the eribulin-trastuzumab-pertuzumab (ETP) regimen as first-line therapy for patients with HER2-positive MBC.

\section{Methods}

\section{Study design}

This phase II, multicenter, collaborative, open-label, singlearm study was conducted to examine the usefulness of the ETP regimen as "first-line" therapy for patients with HER2postive MBC who had inoperable breast cancer (stage IV) or recurrence after surgery at the time of initial visit. The study protocol was approved by the Institutional or Central Ethics Committee, and the study was conducted in accordance with the Declaration of Helsinki, Good Clinical Practice, as well as local ethical and legal regulations. All patients provided written informed consent before enrollment. The present study was registered (University Hospital Medical Information Network identifier: 000021585). The cutoff point for the data reported herein was 9 months following the enrollment of the last patient.

\section{Patients}

Female patients were considered eligible for inclusion in the present study when meeting the following criteria: diagnosed with histologically invasive breast cancer; being $\geq 18$ years old and having an expectable prognosis; HER2 overexpression (immunohistochemistry 3-positive or fluorescence in situ hybridization-positive) in the primary or metastatic tumor; firstline therapy for a patient who had inoperable breast cancer (stage IV) at the time of initial visit or recurrence after surgery; Eastern Cooperative Oncology Group [ECOG] performance status 0 or 1; a definite metastatic lesion that is assessed according to the Japanese version of the Response Evaluation Criteria in Solid Tumors (RECIST) version 1.1 [24]; conserved function of major organs; hematology and blood chemistry variables within 14 days prior to enrollment that meet all of the following levels $-\geq 1500 / \mathrm{mm}^{3}$ in neutrophil count, $\geq 75,000 / \mathrm{mm}^{3}$ in platelet count, $\geq 9.0 \mathrm{~g} / \mathrm{dL}$ in hemoglobin, $\leq 2.0 \mathrm{mg} / \mathrm{dL}$ in total bilirubin, and $<100 \mathrm{IU} / \mathrm{L}$ in aspartate aminotransferase and alanine aminotransferase, and $<1.5 \mathrm{mg} / \mathrm{dL}$ in serum creatinine; no clinical problem in electrocardiography; $\geq 55 \%$ in left ventricular ejection fraction in electrocardiography; and written informed consent provided by the patient herself. Patients were excluded when falling under any of the following key criteria: being complicated by an infection or being suspected of an infection because of fever; severe drug allergy; severe renal or hepatic disorder; voluminous pleural effusion or ascites; being or suspected of being pregnant; active double cancer; metachronous or 
simultaneous bilateral breast cancer; active brain metastasis; and being assessed ineligible for the study by the investigator.

\section{Treatment}

Patients underwent study treatments as scheduled (Fig. 1). Concretely, patients received eribulin mesylate $1.4 \mathrm{mg} / \mathrm{m}^{2}$ as a 2- to 5-min intravenous (IV) infusion on days 1 and 8 of each 21-day cycle, trastuzumab $8 \mathrm{mg} / \mathrm{kg}$ as the initial 90-min IV infusion and $6 \mathrm{mg} / \mathrm{kg}$ as the second and subsequent $30-\mathrm{min}$ IV infusions in each 21-day cycle, and pertuzumab $840 \mathrm{mg} /$ body as the initial 60-min IV infusion and $420 \mathrm{mg} /$ body as the second and subsequent 30-min IV infusions in each 21day cycle. Treatment cycles consisting of 2 doses of eribulin and 7-day drug holiday were repeated until treatment discontinuation. Patients were treated with trastuzumab and pertuzumab when dose reductions of eribulin failed to resolve treatment-emergent adverse events (TEAEs). Two dose reductions $\left(1.1\right.$ and $\left.0.7 \mathrm{mg} / \mathrm{m}^{2}\right)$ were permitted for eribulin, but not for trastuzumab and pertuzumab. Furthermore, patients were allowed to remain on study treatment until failure in obtaining additional clinical benefit, disease progression, occurrence of unacceptable AEs, or withdrawal of consent to study participation.

\section{Assessment of efficacy}

The investigator assessed tumor lesions according to the Japanese version of the RECIST version 1.1 [24] at screening, at week 6 ( \pm 3 weeks) after the day of first dosing, and every
6 weeks ( \pm 3 weeks) from the prior date of tumor lesion assessment. The primary endpoint was the overall response rate (ORR: the proportion of patients who gained complete response $[\mathrm{CR}]$ plus those who gained partial response [PR]). $\mathrm{CR}$ was defined as the disappearance of all target lesions on the basis of results from imaging modalities (i.e., computed tomography and magnetic resonance imaging). PR was defined as $a \geq 30 \%$ reduction in the diameter sum of target lesions as compared with that found at baseline. Progressive disease (PD) was defined as $\mathrm{a} \geq 20 \%$ increase in the diameter sum of target lesions as compared with the minimal diameter sum during the clinical course, and $\mathrm{a} \geq 5 \mathrm{~mm}$ increase in the absolute value of diameter sum. The secondary endpoints were the time to treatment failure (TTF: a composite of disease progression, death, discontinuation of treatment, or switch to other types of antitumor therapy), progression-free survival (PFS: the time from enrollment to the first documented evidence of PD or death from any cause), and TEAEs of ETP therapy. In addition, the clinical benefit rate (CBR: CR + $\mathrm{PR}+$ long-term stable disease [LSD] $\geq 24$ weeks) and the disease control rate (DCR: $\mathrm{CR}+\mathrm{PR}+$ stable disease [SD]) were calculated. Best overall responses were determined and recorded, and percentage changes in the total sum of target lesion diameters were calculated.

\section{Safety}

The investigator monitored and graded TEAEs according to the Japanese version of the National Cancer Institute Common Terminology Criteria for Adverse Events (CTCAE) version
Fig. 1 Dosing schedule of study drugs. HER2, human epidermal growth factor receptor 2; IHC, immunohistochemistry; FISH, fluorescence in situ hybridization; DISH, dual-color in situ hybridization; $\mathrm{P}$, pertuzumab; $\mathrm{T}$, trastuzumab; E, eribulin

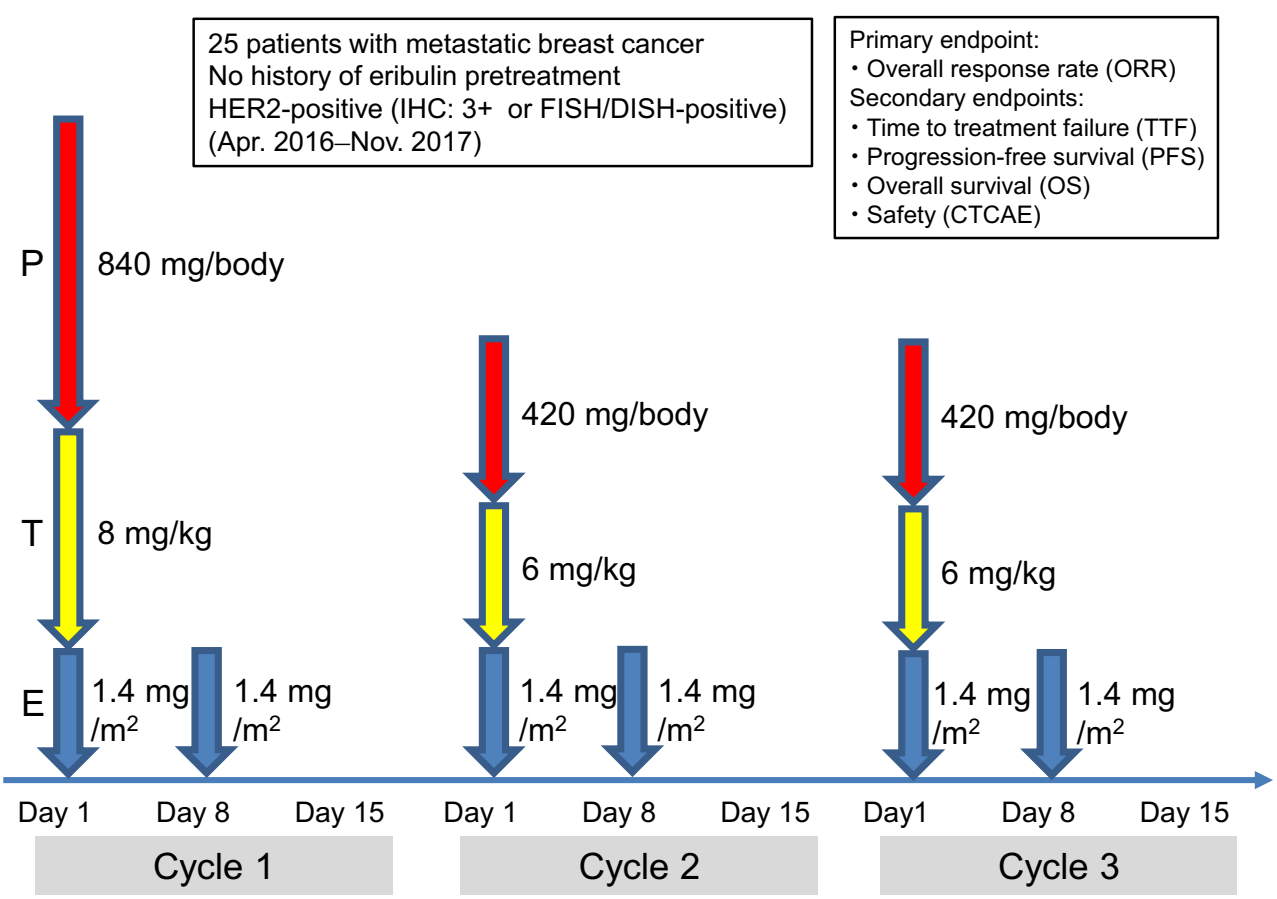

$P$, pertuzumab; $T$, trastuzumab; $E$, eribulin 
4.03 [25] with respect to the prespecified safety valuables (e.g., periodic measurements of subjective symptoms, objective signs, physical examinations, vital signs, hematology, blood chemistry, and imaging modalities) at baseline, every 9 weeks after the onset of treatment, and at the time when study treatment was completed or discontinued. Furthermore, an independent efficacy and safety evaluation committee assessed the incidence and severity of TEAEs.

\section{Statistical analyses}

Due to the small sample size, formal statistical analyzes were not planned for this study. In consideration of the results from the CLEOPATRA study [8-10], however, we expected an ORR of approximately $80 \%$ for ETP therapy. The target number of patients was calculated to be 16 based on the following statistical conditions: $90 \%$ confidence interval [CI]: 0.16, twosided; duration of enrollment: 12 months; duration of followup to assess the OS after the completion of enrollment: 48 months: $\alpha$ level: 0.05 ; and power: $80 \%$. SPSS version 19 (IBM, Armonk, NY) was used to make all statistical analyses.

\section{Results}

\section{Patients}

A total of 25 female patients (median age: 57 years [41-75]) were enrolled from April 18, 2016, through November 22, 2017, at 7 medical institutions in Japan. Demographic and clinical characteristics of patients at baseline are shown in Table 1. Among them, 24 had ECOG performance status (PS) 0, 1 PS 1, 8 stage IV breast cancer, and 17 recurrence after surgery. Anthracyclines, taxanes, and trastuzumab were administered in the neoadjuvant and adjuvant pharmacotherapies settings to 13,15 , and 14 patients, respectively. Overall, 48.0\% ( $n=12), 20.0 \%(n=5)$, and $44.0 \%(n=11)$ had estrogen receptor-, progesterone receptor-, and HER2-positive disease. The most common metastatic sites were the lung (36\%, $n=9)$, liver $(36 \%, n=9)$, and bone $(24 \%, n=6)$.

\section{Study drug exposure}

Patients received a median number of 10 cycles (range, 0-34) of treatment with eribulin during a median of 6.9 months of treatment (range, 2.1-26.2; Table 2). A reduction in eribulin dose from 1.4 to $1.1 \mathrm{mg} / \mathrm{m}^{2}$ after cycle 1 was required in 5 (20.0\%) patients; among them, $3(12.0 \%)$ patients required a further reduction to $0.7 \mathrm{mg} / \mathrm{m}^{2}$. Furthermore, 1 patient required a reduction in eribulin dose directly from 1.4 to $0.7 \mathrm{mg} / \mathrm{m}^{2}$ for the sake of safety. Dose omissions, reductions, delays, and interruptions occurred in $18,6,4$, and 7 patients, respectively.

\section{Efficacy}

With the exception of 1 patient who was not evaluable due to the grade 3 infusion reaction of pertuzumab, 24 were evaluable for best overall responses (Table 3 ). The ORR was $80.0 \%$ (95\% CI, 59.3-93.2\%). Furthermore, 3 (12.0\%), 17 $(68.0 \%), 1(4.0 \%), 1(4.0 \%)$, and $2(8.0 \%)$ patients showed $\mathrm{CR}, \mathrm{PR}$, long-term stable disease (LSD), stable disease (SD), and PD, respectively. The median TTF with eribulin was 9.1 months (95\% CI, 4.3-13.9 months; Fig. 2a), and the median TTF with trastuzumab and pertuzumab was 17.7 months (95\% CI, 13.6-21.8 months (Fig. 2b). The median PFS was 23.1 months (95\% CI, 14.4-31.8 months; Fig. 3). The CBR was $84.0 \%$ (95\% CI, 63.9-95.5\%). The disease control rate (DCR)-defined as the summed proportion of patients who achieved CR, PR, LSD, and SD - was $88.0 \%$ (95\% CI: 68.8$97.5 \%)$. Twenty-one $(87.5 \%)$ among 24 evaluable patients showed reductions in the diameters of overall target lesions including the liver, lung, and others (Fig. 4).

\section{Safety}

TEAEs occurred in all patients (Table 4). The most common TEAEs (all grades occurring in $\geq 40 \%$ of patients) were alopecia $(92.0 \%, n=23)$, fatigue $(68.0 \%, n=17)$, sensory peripheral neuropathy $(60.0 \%, n=15)$, anorexia $(48.0 \%, n=$ $12)$, anemia, $(44.0 \%, n=11)$, and white blood cell count decreased $(40.0 \%, n=10)$. Grade $3 / 4$ TEAEs occurred in 11 $(44.0 \%)$ patients. The most common grade 3 TEAEs (occurring in $\geq 10.0 \%$ of patients) were white blood cell count decreased, neutrophil count decreased, and anemia (12.0\% each, $n=3)$. The only grade 4 TEAE observed was neutrophil count decreased $(16.0 \%, n=4)$; none of these patients required treatment with granulocyte colony-stimulating factors. No febrile neutropenia or cardiac dysfunction occurred. Six patients experienced disease progression, 3 of whom died.

\section{Discussion}

This is the first phase II clinical trial of ETP therapy for patients with HER2-positive MBC and exhibited the efficacy variables that were equivalent to those of the pivotal study CLEOPATRA study [8]: an ORR of $80.0 \%(n=20)$ vs. $80.2 \%(n=275)$, the median PFS of 23.1 months vs. 18.5 months, and the number of cycles of $10 \mathrm{vs}$. 8 . We speculate that these clinical outcomes are attributable to the following facts: 1) this study was designed as "first-line" therapy for this patient population; 2) eribulin, a drug with welldemonstrated efficacy in clinical studies, was administered to patients who were naïve to the drug; and 3) drug exposure as assessed by the number of cycles was greater to eribulin than to docetaxel. The incidence of neutrophil count decreased 
Table 1 Demographic and clinical characteristics of patients at baseline $(N=25)$

\begin{tabular}{|c|c|c|}
\hline Characteristic & $\mathrm{n}$ & $\%$ \\
\hline \multicolumn{3}{|l|}{ Age, years } \\
\hline Median & 57 & \\
\hline \multirow{2}{*}{\multicolumn{3}{|c|}{ Status of menopause }} \\
\hline & & \\
\hline Premenopause & 5 & 20.0 \\
\hline Postmenopause & 20 & 80.0 \\
\hline \multicolumn{3}{|l|}{ Stage } \\
\hline IV & 8 & 32.0 \\
\hline Recurrence after surgery & 17 & 68.0 \\
\hline \multicolumn{3}{|l|}{ ECOG performance status } \\
\hline 0 & 24 & 96.0 \\
\hline 1 & 1 & 4.0 \\
\hline \multicolumn{3}{|l|}{ Histopathology } \\
\hline Common type & 25 & 100.0 \\
\hline \multicolumn{3}{|l|}{ ER status } \\
\hline Positive & 12 & 48.0 \\
\hline Negative & 13 & 52.0 \\
\hline \multicolumn{3}{|l|}{ PgR status } \\
\hline Positive & 5 & 20.0 \\
\hline \multirow{2}{*}{\multicolumn{3}{|c|}{ HER2 status }} \\
\hline & & \\
\hline \multicolumn{3}{|l|}{ Herceptest ${ }^{\circledR} /$ FISH or DISH } \\
\hline $3+/$ not evaluable & 11 & 44.0 \\
\hline $3+/$ positive & 8 & 32.0 \\
\hline 2+/positive & 5 & 20.0 \\
\hline Not evaluable/positive & 1 & 4.0 \\
\hline \multicolumn{3}{|c|}{ Prior adjuvant or neoadjuvant chemotherapy with anthracyclines } \\
\hline Present & 13 & 52.0 \\
\hline Absent & 12 & 48.0 \\
\hline \multicolumn{3}{|c|}{ Prior adjuvant or neoadjuvant chemotherapy with taxanes } \\
\hline Present & 15 & 60.0 \\
\hline Absent & 10 & 40.0 \\
\hline \multicolumn{3}{|c|}{ Prior adjuvant or neoadjuvant chemotherapy with trastuzumab } \\
\hline Absent & 11 & 44.0 \\
\hline \multicolumn{3}{|c|}{ Prior adjuvant or neoadjuvant hormone therapy } \\
\hline Present & 9 & 36.0 \\
\hline \multirow{2}{*}{\multicolumn{3}{|c|}{ Current hormone therapy }} \\
\hline & & \\
\hline Present & 2 & 8.0 \\
\hline Absent & 23 & 92.0 \\
\hline Combination treatment wi & & \\
\hline Denosumab & 3 & 12.0 \\
\hline Zolodronate & 2 & 8.0 \\
\hline Metastatic sites & & \\
\hline 3 & 8 & 32.0 \\
\hline 4 & 2 & 8.0 \\
\hline Visceral metastases & & \\
\hline Present & 14 & 56.0 \\
\hline Absent & 11 & 44.0 \\
\hline Lung metastasis & & \\
\hline Present & 9 & 36.0 \\
\hline Absent & 16 & 64.0 \\
\hline Liver metastasis & & \\
\hline Present & 9 & 36.0 \\
\hline Absent & 16 & 64.0 \\
\hline Local lesion & & \\
\hline Present & 12 & 48.0 \\
\hline Absent & 13 & 52.0 \\
\hline Lymph node metastasis & & \\
\hline Present & 16 & 64.0 \\
\hline Absent & 9 & 36.0 \\
\hline Skin metastasis & & \\
\hline Present & 3 & 12.0 \\
\hline Absent & 22 & 88.0 \\
\hline Bone metastasis & & \\
\hline Present & 6 & 24.0 \\
\hline Absent & 19 & 76.0 \\
\hline
\end{tabular}

ECOG Eastern Cooperative Oncology Group, ER estrogen receptor, $P g R$ progesterone receptor, HER2 human epidermal growth factor receptor 2, FISH fluorescence in situ hybridization, $D I S H$ dual-color in situ hybridization 
Table 2 Study drug exposure

\begin{tabular}{ll}
\hline & DTP $(N=25)$ \\
\hline $\begin{array}{l}\text { Number of cycles delivered } \\
\text { Median (range) for trastuzumab }\end{array}$ & \\
Median (range) for pertuzumab & 14.5 cycles $(3-36)$ \\
Median (range) for eribulin & 14.5 cycles $(0-34)$ \\
Relative dose intensity $(\%)$ & 10.0 cycles $(3-34)$ \\
Median (range) for trastuzumab & \\
Median (range) for pertuzumab & $97.1 \%(29.0-104.5)$ \\
Median (range) for eribulin & $95.1 \%(0-104.5)$ \\
Dose omissions*, $\mathrm{n}(\%)$ & $96.4 \%(23.3-115.4)$ \\
Dose reductions, $\mathrm{n}(\%)$ & $18(72.0 \%)$ \\
Dose delays, $\mathrm{n}(\%)$ & $6(24.0 \%)$ \\
Dose interruptions & \\
\hline
\end{tabular}

*The same patients had several reasons

**The same patients had several adverse events

(all grades) was markedly lower in our study (32.0\%) than in the CLEOPATRA study (52.8\%). The median RDI for eribulin was $96.4 \%$, indicating that most patients received the planned dose of $1.4 \mathrm{mg} / \mathrm{m}^{2}$ on days 1 and 8 of each 21 day cycle. ETP therapy caused grade $3 / 4$ neutrophil count decreased $(28.0 \%)$ without causing febrile neutropenia. In general, severe (grade 3/4) peripheral neuropathy occurs in up to $30 \%$ of patients who are treated with microtubuletargeting chemotherapy agents including taxanes and epothilones [26]. Therefore, the facts that the incidences of grade 3 sensory peripheral neuropathy, grade 4 sensory and motor peripheral neuropathies, as well as febrile neutropenia were as low as $4 \%$ ( $1 / 25$ patients), $0 \%$ (0/25 patients), $0 \%$ ( $0 / 25$ patients), respectively, are of particular note when considering the potential contribution of 10 cycles [median] of eribulin to cumulative neuropathic toxicities as compared with

Table 3 Efficacy outcomes

\begin{tabular}{llll}
\hline Best overall response & All $(N=25)$ & Percent & $95 \%$ CI \\
\hline CR & 3 & 12.0 & $2.6-31.2$ \\
PR & 17 & 68.0 & $46.5-85.1$ \\
LSD & 1 & 4.0 & $0.1-20.4$ \\
SD & 1 & 4.0 & $0.1-20.4$ \\
PD & 2 & 8.0 & $1.0-26.0$ \\
NE & 1 & 4.0 & $0.1-20.4$ \\
ORR (CR + PR) & 20 & 80.0 & $59.3-93.2$ \\
CBR (CR + PR + LSD) & 21 & 84.0 & $63.9-95.5$ \\
DCR (CR + PR + LSD + SD) & 22 & 88.0 & $68.8-97.5$ \\
\hline
\end{tabular}

$C I$ confidence interval, $C R$ complete response, $P R$ partial response, $L S D$ long-term stable disease $\geq 24$ weeks, $S D$ stable disease $<24$ weeks, $P D$ progressive disease, $N E$ not evaluable, $O R R$ overall response rate, $D C R$ disease control rate, $C B R$ clinical benefit rate

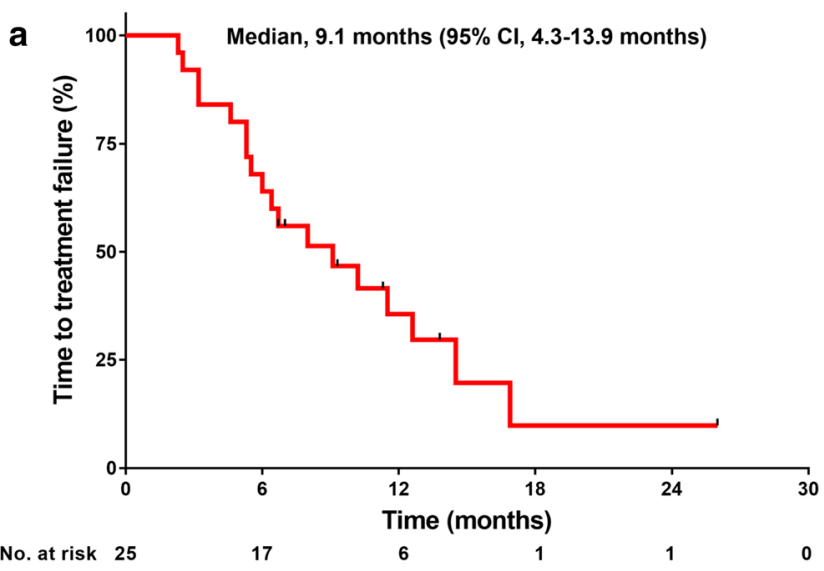

b

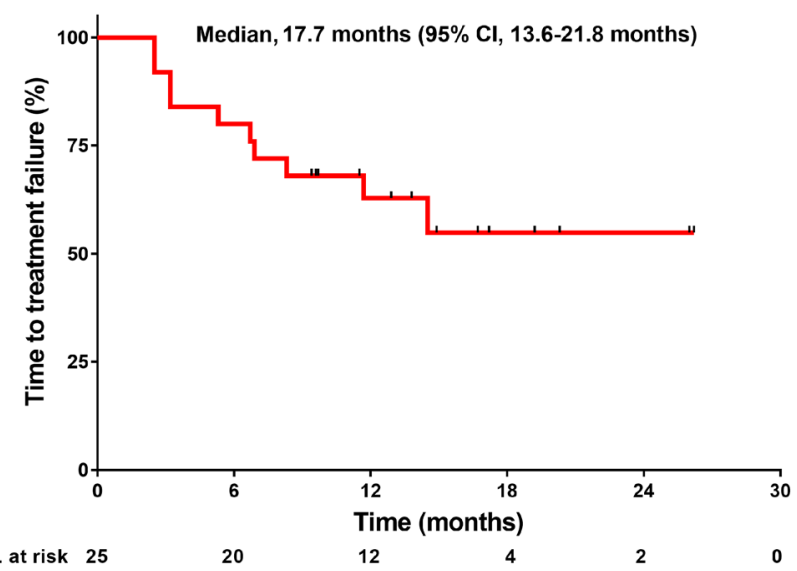

Fig. 2 a Time to treatment failure with eribulin. b Time to treatment failure with trastuzumab and pertuzumab

a median of 8 cycles of docetaxel in the CLEOPATRA study [8]. These findings are in line with the study of Vahdat et al. [14] that reported $9.8 \%$ and $20.0 \%$ in the incidences of grade 3 peripheral neuropathy for eribulin and ixabepilone-a microtubule stabilizer derived from epothilone B, respectively, and no case of grade 4 peripheral neuropathy for both drugs in the fewer median numbers of 5.0 and 3.5 cycles, respectively.

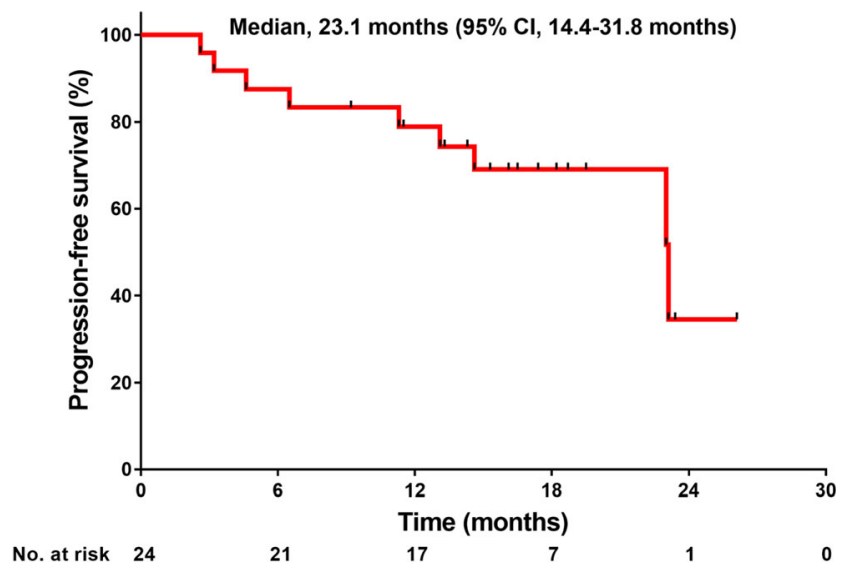

Fig. 3 Progression-free survival 


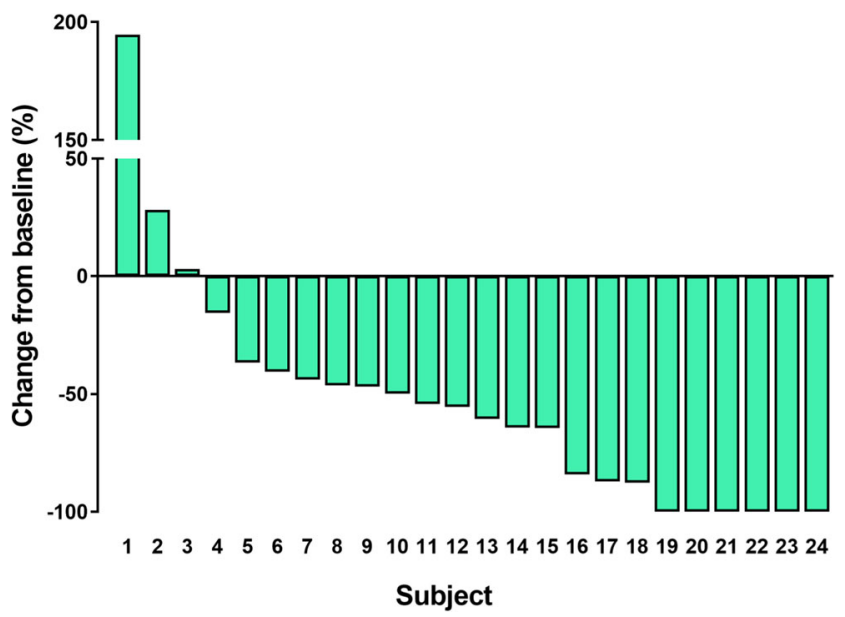

Fig. 4 Waterfall plots of percentage changes in the total sum of the longest single diameter for measurable target lesions from baseline to the maximal tumor shrinkage regarding best overall responses: overall target lesions including the liver, lung, and others

DTP therapy is recommended by the National Comprehensive Cancer Network guidelines as preferred first-line therapy for the treatment of patients with HER2- positive MBC [27]. The guidelines list the combinations of trastuzumab plus paclitaxel \pm carboplatin, docetaxel, vinorelbine, and capecitabine as first-line treatment for HER2positive disease. Docetaxel, one of the most active chemotherapeutic agents used in the treatment of MBC [28] and forms the taxane component of the standard treatment for patients with HER2-positive MBC, often impedes the triple therapy due to various reasons (e.g., a history of taxane allergy, resistance/refractoriness to or intolerance of taxanes, and acute/cumulative toxicities) [11]. Therefore, an effective and less toxic chemotherapy regimen combining a nontaxane drug with trastuzumab and pertuzumab is required as a therapeutic option for some patients with such inconveniences.

Eribulin, a novel nontaxane compound derived from halichondrin $\mathrm{B}$, offers the following clinical advantages: 1 ) a rapid infusion time as short as 2 to $5 \mathrm{~min} ; 2$ ) no need for the use of solvents that taxanes necessitate (polysorbate 80 for docetaxel and Cremophor ${ }^{\circledR}$ EL for paclitaxel) - a procedure responsible for hypersensitivity reactions [13], thus leading to the avoidance of steroid premedication and to prevent the reactions; and 3) good efficacy and tolerability for heavily
Table 4 Treatment-emergent adverse events by CTCAE grade in the safety population*

\begin{tabular}{|c|c|c|c|c|c|}
\hline \multirow[t]{2}{*}{ TEAEs } & \multicolumn{5}{|c|}{ Severity, N (\%) } \\
\hline & All grades & Grade 1 & Grade 2 & Grade 3 & Grade 4 \\
\hline \multicolumn{6}{|l|}{ Hematologic toxicities $(n=25)$} \\
\hline White blood cell count decreased & $10(40.0)$ & $3(12.0)$ & $4(16.0)$ & $3(12.0)$ & $0(0)$ \\
\hline Neutrophil count decreased & $8(32.0)$ & $1(4.0)$ & $0(0)$ & $3(12.0)$ & $4(16.0)$ \\
\hline Anemia & $11(44.0)$ & $7(28.0)$ & $1(4.0)$ & $3(12.0)$ & $0(0)$ \\
\hline Aspartate aminotransferase increased & $6(24.0)$ & $4(16.0)$ & $2(8.0)$ & $0(0)$ & $0(0)$ \\
\hline Alanine aminotransferase increased & $7(28.0)$ & $4(16.0)$ & $3(120)$ & $0(0)$ & $0(0)$ \\
\hline Blood bilirubin increased & $3(12.0)$ & $1(4.0)$ & $2(8.0)$ & $0(0)$ & $0(0)$ \\
\hline Creatinine increased & $5(20.0)$ & $4(16.0)$ & $1(4.0)$ & $0(0)$ & $0(0)$ \\
\hline Platelet count decreased & $0(0)$ & $0(0)$ & $0(0)$ & $0(0)$ & $0(0)$ \\
\hline \multicolumn{6}{|l|}{ Nonhematologic toxicities $(n=25)$} \\
\hline Alopecia & $23(92.0)$ & $13(52.0)$ & $10(40.0)$ & - & - \\
\hline Fatigue & $17(68.0)$ & $8(32.0)$ & $7(28.0)$ & $2(8.0)$ & $0(0)$ \\
\hline Sensory peripheral neuropathy & $15(60.0)$ & $12(48.0)$ & $2(8.0)$ & $1(4.0)$ & $0(0)$ \\
\hline Anorexia & $12(48.0)$ & $7(28.0)$ & $4(16.0)$ & $1(4.0)$ & $0(0)$ \\
\hline Mucositis oral & $9(36.0)$ & $9(36.0)$ & $0(0)$ & $0(0)$ & $0(0)$ \\
\hline Motor peripheral neuropathy & $8(32.0)$ & $4(16.0)$ & $4(16.0)$ & $0(0)$ & $0(0)$ \\
\hline Diarrhea & $7(28.0)$ & $5(20.0)$ & $2(8.0)$ & $0(0)$ & $0(0)$ \\
\hline Arthralgia & $6(24.0)$ & $4(16.0)$ & $2(8.0)$ & $0(0)$ & $0(0)$ \\
\hline Myalgia & $5(20.0)$ & $4(16.0)$ & $0(0)$ & $1(4.0)$ & $0(0)$ \\
\hline Nausea & $5(20.0)$ & $5(20.0)$ & $0(0)$ & $0(0)$ & $0(0)$ \\
\hline Nail discoloration & $4(16.0)$ & $4(16.0)$ & - & - & - \\
\hline Dysgeusia & $4(16.0)$ & $2(8.0)$ & $2(8.0)$ & - & - \\
\hline Rash & $3(12.0)$ & $3(12.0)$ & $0(0)$ & $0(0)$ & $0(0)$ \\
\hline Vomiting & $3(12.0)$ & $3(12.0)$ & $0(0)$ & $0(0)$ & $0(0)$ \\
\hline Edema limbs & $3(12.0)$ & $3(12.0)$ & $0(0)$ & $0(0)$ & $0(0)$ \\
\hline Lung infection & $1(4.0)$ & $0(0)$ & $0(0)$ & $1(4.0)$ & $0(0)$ \\
\hline Infusion-related reaction by pertuzumab & $1(4.0)$ & $0(0)$ & $0(0)$ & $1(4.0)$ & $0(0)$ \\
\hline Constipation & $1(4.0)$ & $1(4.0)$ & $0(0)$ & $0(0)$ & $0(0)$ \\
\hline Epistaxis & $1(4.0)$ & $1(4.0)$ & $0(0)$ & $0(0)$ & $0(0)$ \\
\hline Olfactory nerve disorder & $1(4.0)$ & $1(4.0)$ & $0(0)$ & $0(0)$ & $0(0)$ \\
\hline Nail loss & $1(4.0)$ & $1(4.0)$ & $0(0)$ & - & - \\
\hline
\end{tabular}

*The safety population consisted of patients who received at least one dose of the study drugs

$C T C A E$ common terminology criteria for adverse events 
pretreated patients who have MBC and well-defined taxane resistance [29]. Based on the favorable tolerability of eribulin in phase I studies for various malignancies (e.g., lung, breast, colorectal cancers), the efficacy and safety of eribulin alone or in combination with various anticancer agents for patients with MBC have been investigated in a number of phase II [14-19] and III [20-22] studies. Results from these previous clinical studies have indicated the following efficacy variables: ORRs ranging from 9.3 to $80.2 \%$; median PFSs ranging from 2.6 to 18.7 months; median OSs ranging from 9.0 to 56.5 months; and DCRs ranging 55.3 to $96.2 \%$.

To date, furthermore, a diversity of first-line therapeutic regimens have been explored for patients with HER2positive MBC. In a randomized phase 3 clinical study of trastuzumab monotherapy followed by trastuzumab plus docetaxel versus trastuzumab plus docetaxel [30], we demonstrated that the concurrent administration of trastuzumab and docetaxel was superior in OS to the sequential administration of trastuzumab followed by trastuzumab plus docetaxel. Several clinical studies have shown the efficacy and safety of trastuzumab and/or pertuzumab in combination with chemotherapeutic agents including docetaxel, paclitaxel, vinorelbine, and capecitabine in patients with HER2-positive MBC [6-8, 31-34]. Recently, Sakaguchi et al. conducted a multicenter, single-arm, phase II clinical trial of first-line eribulin and trastuzumab in 28 Japanese women with naïve progressive or recurrent HER2-positive breast cancer [35]. Patients received a median of 12 cycles (range, 2-53 cycles). They reported the following efficacy variables: the ORR, 53.6\% (90\% CI, 36.6-69.9); the CBR, 64.0\% (90\% CI, 45.6179.76); and the median PFS, 344 days (95\% CI, $237-$ 680 days). In consideration of these data, namely, ours (ORR, 80.0\%; CBR, 84.0\%; and; and median PFS, 23.1 months) exhibited the improving-effect of pertuzumab on the efficacy variables. Grade 3/4 AEs occurred in $42.9 \%$ of patients. The most common AEs were sensory peripheral neuropathy $(67.9 \%)$ and white blood cell count decreased (50.0\%). They concluded that the eribulin-trastuzumab combination is a potentially important first-line option for advanced and recurrent HER2-positive breast cancer. In addition, Tono et al. conducted a single center feasibility study of ETP therapy in 10 Japanese women with previously treated advanced HER2-positive breast cancer to investigate the safety of ETP therapy and the QOL of patients, as well as to analyze biomarkers (e.g., serum HER2 extracellular domain [sHER] levels, PIK3CA gene mutation status, and circulating peripheral regulatory T cell levels) [36]. The median PFS was 4.8 months (95\% CI, 3.7-5.9 months), the ORR was $20.0 \%$, and the DCR was $70.0 \%$. The most common grade 3 AEs were leukopenia and neutropenia $(70.0 \%$, respectively), and grade 4/5 AEs were not observed. The QOL scores exhibited an improvement trend at 3 months of the therapy. They found a strong association between the baseline sHER level and the serum trastuzumab trough concentration at 3 months of the therapy and concluded that ETP therapy might be a feasible option for patients with HER2-positive MBC that has wildtype or mutated PIK3CA. These most recent clinical studies, published in 2018, provide clinical evidence on the efficacy and safety of the double and triple chemotherapy regimens of eribulin in combination with trastuzumab \pm pertuzumab, thus serving to strengthen the rationale and clinical relevance of ETP therapy for patients with HER2-positive MBC.

The present study has several limitations. First, sample size was small because of its nature of being a phase 2 clinical trial; however, the enrolled number of patients exceeded the scheduled number of patients- 16 and was good enough for the analyses of efficacy variables. Second, the survival data were not mature at the time of clinical data cutoff. Nevertheless, we consider that the obtained data on the efficacy and safety of ETP therapy are sufficient as the preliminary clinical data to consider its potential of becoming an alternative regimen for the well-established first-line therapy using DTP.

\section{Conclusions}

Triple therapy consisting of eribulin, trastuzumab, and pertuzumab provided a high ORR, a prolonged PFS, and an acceptable safety profile. Therefore, ETP therapy is a potentially important first-line therapy for patients with HER2positive MBC. EMERALD, a phase III taxane-controlled clinical trial of eribulin, trastuzumab, and pertuzumab in Japan, is ongoing.

Acknowledgements The authors thank Satoshi Sakima, MD, for valuable discussion about the manuscript, and to Junichi Koh, $\mathrm{MD}, \mathrm{PhD}$, for his technical support.

Funding This research was supported by the Practical Research for Innovative Cancer Control (18ck0106307h0002) from Japan Agency for Medical Research and Development, AMED.

\section{Compliance with ethical standards}

Conflict of interest Dr. Inoue received grant from Novartis, Pfizer, Chugai, Daiichi-Sankyo, Parexel/Puma Biotechnology, MSD, Bayer, Lilly, and Eisai during the conduct of the study. The other authors declare that they have no conflict of interest.

Ethical approval All procedures performed in studies involving human participants were in accordance with the ethical standards of the institutional and/or national research committee and with the 1964 Helsinki declaration and its later amendments or comparable ethical standards. This article does not contain any studies with animals performed by any of the authors. The study protocol was approved by the Medical Ethics Committees of the participating institutions.

Informed consent Informed consent was obtained from all individual participants included in the study. 
Open Access This article is distributed under the terms of the Creative Commons Attribution 4.0 International License (http:// creativecommons.org/licenses/by/4.0/), which permits unrestricted use, distribution, and reproduction in any medium, provided you give appropriate credit to the original author(s) and the source, provide a link to the Creative Commons license, and indicate if changes were made.

\section{References}

1. Slamon DJ, Clark GM, Wong SG, Levin WJ, Ullrich A, McGuire WL (1987) Human breast cancer: correlation of relapse and survival with amplification of the HER-2/neu oncogene. Science 235(4785):177-182

2. Slamon DJ, Godolphin W, Jones LA, Holt JA, Wong SG, Keith DE, Levin WJ, Stuart SG, Udove J, Ullrich A, Press MFD (1989) Studies of the HER-2/neu proto-oncogene in human breast and ovarian cancer. Science 244(4905):707-712

3. Jemal A, Bray F, Center MM, Ferlay J, Ward E, Forman D (2011) Global cancer statistics. CA Cancer J Clin 61(2):69-90. https://doi. org/10.3322/caac.20107

4. McGuire A, Brown JA, Kerin MJ (2015) Metastatic breast cancer: the potential of miRNA for diagnosis and treatment monitoring. Cancer Metastasis Rev 34(1):145-155. https://doi.org/10.1007/ s10555-015-9551-7

5. Larionob (2018) Current therapies for human epidermal growth factor receptor 2-positive metastatic breast cancer patients. Front Oncol 8(89). https://doi.org/10.3389/fonc.2018.00089

6. Slamon DJ, Leyland-Jones B, Shak S, Fuchs H, Paton V, Bajamonde A, Fleming T, Eiermann W, Wolter J, Pegram M, Baselga J, Norton L (2001) Use of chemotherapy plus a monoclonal antibody against HER2 for metastatic breast cancer that overexpresses HER2. N Engl J Med 344(11):783-792

7. Marty M, Cognetti F, Maraninchi D, Snyder R, Mauriac L, Tubiana-Hulin M, Chan S, Grimes D, Antón A, Lluch A, Kennedy J, O'Byrne K, Conte P, Green M, Ward C, Mayne K, Extra JM (2005) Randomized phase II trial of the efficacy and safety of trastuzumab combined with docetaxel in patients with human epidermal growth factor receptor 2-positive metastatic breast cancer administered as first-line treatment: the M77001 study group. J Clin Oncol 23(19):4265-4274

8. Baselga J, Cortés J, Kim SB, Im SA, Hegg R, Im YH, Roman L, Pedrini JL, Pienkowski T, Knott A, Clark E, Benyunes MC, Ross G, Swain SM, CLEOPATRA Study Group (2012) Pertuzumab plus trastuzumab plus docetaxel for metastatic breast cancer. N Engl J Med 366(2):109-119. https://doi.org/10.1056/NEJMoa1113216

9. Swain SM, Kim SB, Cortés J, Ro J, Semiglazov V, Campone M, Ciruelos E, Ferrero JM, Schneeweiss A, Knott A, Clark E, Ross G, Benyunes MC, Baselga J (2013) Pertuzumab, trastuzumab, and docetaxel for HER2-positive metastatic breast cancer (CLEOPATRA study): overall survival results from a randomised, double-blind, placebo-controlled, phase 3 study. Lancet Oncol 14(6):461-471. https://doi.org/10.1016/S1470-2045(13)70130-X

10. Swain SM, Baselga J, Kim SB, Ro J, Semiglazov V, Campone M, Ciruelos E, Ferrero JM, Schneeweiss A, Heeson S, Clark E, Ross G, Benyunes MC, Cortés J, CLEOPATRA Study Group (2015) Pertuzumab, trastuzumab, and docetaxel in HER2-positive metastatic breast cancer. N Engl J Med 372(8):724-734. https://doi.org/10. 1056/NEJMoa1413513

11. Ho MY, Mackey JR (2014) Presentation and management of docetaxel-related adverse effects in patients with breast cancer. Cancer Manag Res 6:253-259. https://doi.org/10.2147/CMAR. S40601
12. Koczywas M, Frankel PH, Synold TW, Lenz HJ, Mortimer JE, ElKhoueiry AB, Gandara DR, Cristea MC, Chung VM, Lim D, Reckamp KL, Lau DH, Doyle LA, Ruel C, Carroll MI, Newman EM (2014) Phase I study of the halichondrin B analogue eribulin mesylate in combination with cisplatin in advanced solid tumors. $\mathrm{Br}$ J Cancer 111(12):2268-2274. https://doi.org/10.1038/bjc.2014.554

13. Doherty MK, Morris PG (2015) Eribulin for the treatment of metastatic breast cancer: an update on its safety and efficacy. Int $\mathrm{J}$ Women's Health 7:47-58. https://doi.org/10.2147/IJWH.S74462

14. Vahdat LT, Pruitt B, Fabian CJ, Rivera RR, Smith DA, Tan-Chiu E, Wright J, Tan AR, Dacosta NA, Chuang E, Smith J, O'Shaughnessy J, Shuster DE, Meneses NL, Chandrawansa K, Fang F, Cole PE, Ashworth S, Blum JL (2009) Phase II study of eribulin mesylate, a halichondrin B analog, in patients with metastatic breast cancer previously treated with an anthracycline and a taxane. J Clin Oncol 27(18):2954-2961. https://doi.org/10.1200/JCO.2008.17. 7618

15. Cortes J, Vahdat L, Blum JL, Twelves C, Campone M, Roché H, Bachelot T, Awada A, Paridaens R, Goncalves A, Shuster DE, Wanders J, Fang F, Gurnani R, Richmond E, Cole PE, Ashworth S, Allison MA (2010) Phase II study of the halichondrin B analog eribulin mesylate in patients with locally advanced or metastatic breast cancer previously treated with an anthracycline, a taxane, and capecitabine. J Clin Oncol 28(25):3922-3928. https://doi.org/ 10.1200/JCO.2009.25.8467

16. Aogi K, Iwata H, Masuda N, Mukai H, Yoshida M, Rai Y, Taguchi K, Sasaki Y, Takashima S (2012) A phase II study of eribulin in Japanese patients with heavily pretreated metastatic breast cancer. Ann Oncol 23(6):1441-1448. https://doi.org/10.1093/annonc/ mdr444

17. McIntyre K, O'Shaughnessy J, Schwartzberg L, Glück S, Berrak E, Song JX, Cox D, Vahdat LT (2014) Phase 2 study of eribulin mesylate as first-line therapy for locally recurrent or metastatic human epidermal growth factor receptor 2-negative breast cancer. Breast Cancer Res Treat 146(2):321-328. https://doi.org/10.1007/s10549014-2923-9

18. Wilks S, Puhalla S, O'Shaughnessy J, Schwartzberg L, Berrak E, Song J, Cox D, Vahdat L (2014) Phase 2, multicenter, single-arm study of eribulin mesylate with trastuzumab as first-line therapy for locally recurrent or metastatic HER2-positive breast cancer. Clin Breast Cancer 14(6):405-412. https://doi.org/10.1016/j.clbc.2014. 04.004

19. Vahdat LT, Garcia AA, Vogel C, Pellegrino C, Lindquist DL, Iannotti N, Gopalakrishna P, Sparano JA (2013) Eribulin mesylate versus ixabepilone in patients with metastatic breast cancer: a randomized phase II study comparing the incidence of peripheral neuropathy. Breast Cancer Res Treat 140(2):341-351. https://doi.org/ 10.1007/s10549-013-2574-2

20. Cortes J, O'Shaughnessy J, Loesch D, Blum JL, Vahdat LT, Petrakova K, Chollet P, Manikas A, Diéras V, Delozier T, Vladimirov V, Cardoso F, Koh H, Bougnoux P, Dutcus CE, Seegobin S, Mir D, Meneses N, Wanders J, Twelves C, EMBRACE (Eisai Metastatic Breast Cancer Study Assessing Physician's Choice Versus E7389) investigators (2011) Eribulin monotherapy versus treatment of physician's choice in patients with metastatic breast cancer (EMBRACE): a phase 3 open-label randomised study. Lancet 377(9769):914-923. https://doi.org/10. 1016/S0140-6736(11)60070-6

21. Kaufman PA, Awada A, Twelves C, Yelle L, Perez EA, Velikova G, Olivo MS, He Y, Dutcus CE, Cortes J (2015) Phase III open-label randomized study of eribulin mesylate versus capecitabine in patients with locally advanced or metastatic breast cancer previously treated with an anthracycline and a taxane. J Clin Oncol 33(6):594 601. https://doi.org/10.1200/JCO.2013.52.4892

22. Twelves C, Cortes J, Vahdat L, Olivo M, He Y, Kaufman PA, Awada A (2014) Efficacy of eribulin in women with metastatic 
breast cancer: a pooled analysis of two phase 3 studies. Breast Cancer Res Treat 148(3):553-561. https://doi.org/10.1007/ s10549-014-3144-y

23. Watanabe $J$ (2015) Eribulin monotherapy improved survivals in patients with ER-positive HER2-negative metastatic breast cancer in the real world: a single institutional review. Springerplus 4(625): 625. https://doi.org/10.1186/s40064-015-1422-8

24. Eisenhauer EA, Therasse P, Bogaerts J, Schwartz LH, Sargent D, Ford R, Dancey J, Arbuck S, Gwyther S, Mooney M, Rubinstein L, Shankar L, Dodd L, Kaplan R, Lacombe D, Verweij J (2009) New response evaluation criteria in solid tumours: revised RECIST guideline (version 1.1). Eur J Cancer 45(2):228-247. https://doi. org/10.1016/j.ejca.2008.10.026

25. CTCAE 4.03. National Cancer Institute https://evs.nci.nih.gov/ftp1/ CTCAE/About.html. Accessed 19 Jan 2018

26. Lee JJ, Swain SM (2006) Peripheral neuropathy induced by microtubule-stabilizing agents. J Clin Oncol 24(10):1633-1642

27. National Comprehensive Cancer Network. NCCN clinical practice guidelines in oncology (NCCN guidelines): breast Cancer. Fort Washington, PA: National Comprehensive Cancer Network; 2014 https://wwwnccnorg/store/login/loginaspx? ReturnURL = https:// www.nccn.org/professionals/physician_gls/pdf/breast.pdf. Accessed 31 May 2018

28. Crown J (2001) Docetaxel: overview of an active drug for breast cancer. Oncologist 6(Suppl 3):1-4

29. Inoue K, Saito T, Okubo K, Kimizuka K, Yamada H, Sakurai T, Ishizuna K, Hata S, Kai T, Kurosumi M (2016) Phase II clinical study of eribulin monotherapy in Japanese patients with metastatic breast cancer who had well-defined taxane resistance. Breast Cancer Res Treat 157(2):295-305. https://doi.org/10.1007/ s10549-016-3808-x

30. Inoue K, Nakagami K, Mizutani M, Hozumi Y, Fujiwara Y, Masuda N, Tsukamoto F, Saito M, Miura S, Eguchi K, Shinkai T, Ando M, Watanabe T, Masuda N, Ohashi Y, Sano M, Noguchi S (2010) Randomized phase III trial of trastuzumab monotherapy followed by trastuzumab plus docetaxel versus trastuzumab plus docetaxel as first-line therapy in patients with HER2-positive metastatic breast cancer: the JO17360 trial group. Breast Cancer Res Treat 119(1): 127-136. https://doi.org/10.1007/s10549-009-0498-7

31. Dang C, Iyengar N, Datko F, D'Andrea G, Theodoulou M, Dickler M, Goldfarb S, Lake D, Fasano J, Fornier M, Gilewski T, Modi S, Gajria D, Moynahan ME, Hamilton N, Patil S, Jochelson M,
Norton L, Baselga J, Hudis C (2015) Phase II study of paclitaxel given once per week along with trastuzumab and pertuzumab in patients with human epidermal growth factor receptor 2-positive metastatic breast cancer. J Clin Oncol 33(5):442-447. https://doi. org/10.1200/JCO.2014.57.1745

32. Smyth LM, Iyengar NM, Chen MF, Popper SM, Patil S, Wasserheit-Lieblich C, Argolo DF, Singh JC, Chandarlapaty S, Sugarman SM, Comen EA, Drullinsky PR, Traina TA, TrosoSandoval T, Baselga J, Norton L, Hudis CA, Dang CT (2016) Weekly paclitaxel with trastuzumab and pertuzumab in patients with HER2-overexpressing metastatic breast cancer: overall survival and updated progression-free survival results from a phase II study. Breast Cancer Res Treat 158(1):91-97. https://doi.org/10. 1007/s10549-016-3851-7

33. Perez EA, López-Vega JM, Petit T, Zamagni C, Easton V, Kamber J, Restuccia E, Andersson M (2016) Safety and efficacy of vinorelbine in combination with pertuzumab and trastuzumab for first-line treatment of patients with HER2-positive locally advanced or metastatic breast cancer: VELVET cohort 1 final results. Breast Cancer Res 18(1):126

34. Urruticoechea A, Rizwanullah M, Im SA, Ruiz ACS, Láng I, Tomasello G, Douthwaite H, Badovinac Crnjevic T, Heeson S, Eng-Wong J, Muñoz M (2017) Randomized phase III trial of trastuzumab plus capecitabine with or without pertuzumab in patients with human epidermal growth factor receptor 2-positive metastatic breast cancer who experienced disease progression during or after trastuzumab-based therapy. J Clin Oncol 35(26):3030-3038. https://doi.org/10.1200/JCO.2016.70.6267

35. Sakaguchi K, Nakatsukasa K, Koyama H, Kato M, Sakuyama A, Matsuda T, Tsunoda N, Fujiwara I, Yamaguchi M, Tanaka H, Onishi K, Onishi M, Yoshino Y, Kikuchi T, Taguchi T (2018) Phase II clinical trial of first-line eribulin plus trastuzumab for advanced or recurrent HER2-positive breast cancer. Anticancer Res 38(7):4073-4081. https://doi.org/10.21873/anticanres.12697

36. Tono Y, Ishihara M, Miyahara Y, Tamaru S, Oda H, Yamashita Y, Tawara I, Ikeda H, Shiku H, Mizuno T, Katayama N (2018) Pertuzumab, trastuzumab and eribulin mesylate therapy for previously treated advanced HER2-positive breast cancer: a feasibility study with analysis of biomarkers. Oncotarget 9(19):14909-14921. https://doi.org/10.18632/oncotarget.24504

Publisher's note Springer Nature remains neutral with regard to jurisdictional claims in published maps and institutional affiliations. 